\title{
Desenvolvimento, escolarização e síndrome de Down: expectativas maternas ${ }^{1}$
}

\author{
Laura Kolberg Lipp ${ }^{2}$ \\ Fernanda de Oliveira Martini \\ Lisiane Machado de Oliveira-Menegotto \\ Universidade Federação de Estabelecimentos de Ensino Superior em Novo Hamburgo, Novo Hamburgo-RS, Brasil
}

\begin{abstract}
Resumo: O presente estudo teve por objetivo investigar as expectativas maternas em relação ao desenvolvimento e escolarização do filho com síndrome de Down, a partir de uma perspectiva psicanalítica. Foi realizado um estudo qualitativo, por meio de entrevistas, que foram gravadas, transcritas e posteriormente analisadas, a partir de análise qualitativa de conteúdo. Participaram do estudo 12 mães de pessoas com síndrome de Down, com idades entre dois meses e 23 anos. Os resultados revelaram que o diagnóstico de síndrome de Down gera impacto nas mães. Em decorrência disso, as mães apresentaram dificuldade de construir expectativas em relação ao desenvolvimento e escolarização. Ressalta-se a importância do apoio e acompanhamento da mãe, no que se refere ao exercício da maternidade, bem como de professores que acompanharão o aluno com síndrome de Down a partir da idade escolar.
\end{abstract}

Palavras-chave: síndrome de Down, desenvolvimento humano, educação especial.

\section{Development, schooling and Down syndrome: mother's expectations}

\begin{abstract}
The present study aimed to investigate the mother's expectations in relation to the development and schooling of the child with Down's syndrome, based on a psychoanalytic approach. A qualitative study was carried through, by means of interviews, which have been recorded, transcribed and later analyzed, from qualitative content analysis. Twelve mothers of individuals with Down's syndrome, ages between two months and 23 years, have participated of the study. The results have disclosed that the diagnosis of syndrome of Down generates impact in the mothers. In this result, the mothers have presented difficulty to construct positive expectations in relation to the development and schooling of their children. The importance of a support and following closer of the mother is standing out, as for the exercise of the motherhood, as well as of teachers who will follow up the pupil with Down's syndrome in the school age.
\end{abstract}

Keywords: Downs syndrome, human development, special education.

\section{Desarrollo, escolarización y síndrome de Down: expectativas maternas}

\begin{abstract}
Resumen: El presente estudio tuvo por objetivo investigar las expectativas maternas con relación al desarrollo y la escolarización de hijos con síndrome de Down, basado en una discusión psicoanalítica. Fue realizado un estudio cualitativo, a través de entrevistas, que fueron grabadas, transcritas y posteriormente analizadas, a partir del análisis cualitativo de contenido. Participaron del estudio 12 madres de personas con síndromes de Down, entre 2 meses y 23 años de edad. Los resultados revelan que el diagnóstico del síndrome de Down genera un impacto importante en las madres. Como consecuencia de ello, las madres presentan dificultades en construir expectativas respecto al desarrollo y escolarización de los hijos. El artículo destaca la importancia del apoyo y de la atención psicológica a la madre, relacionada al ejercicio de la maternidad, bien como a los maestros que acompañarán el alumno con síndrome de Down a partir de la edad escolar.
\end{abstract}

Palabras clave: síndrome de Down, desarrollo humano, educación inclusiva.

A educação inclusiva tem sido alvo constante de discussões. Embora a legislação vigente seja pontual e incisiva a favor da inclusão, ainda presenciamos manifestações de dúvidas, incertezas e resistências por parte de professores, pais e comunidade em geral. Nesse sentido, é de fundamental importância que possamos contribuir para a implementação de políticas públicas que possibilitem a inclusão, não somente focalizando a escola e os professores, mas também a família,

\footnotetext{
${ }^{1}$ Apoio: FAPERGS. Este trabalho é derivado de uma pesquisa institucional realizada pela primeira e segunda autoras, sob a orientação da terceira autora.

${ }^{2}$ Endereço para correspondência:

Lisiane Machado de Oliveira Menegotto. Rua Aimoré, 420/21, Bairro Ideal, CEP 93.336-150. Novo Hamburgo-RS, Brasil. E-mail:
} lisianeoliveira@feevale.br uma vez que é no seio familiar que podemos encontrar inúmeros obstáculos para o exercício pleno da inclusão (Luiz, Bortoli, Floria-Santos, \& Nascimento, 2008).

Quando falamos de inclusão, é comum voltarmos nossa atenção à escola, sobretudo, à importância da escola receber e garantir a permanência do aluno com necessidades educacionais especiais. No entanto, não podemos desconsiderar o próprio aluno com necessidades educacionais especiais (Omote, Oliveira, Baleotti, \& Martins, 2005). Como o sujeito se constitui sob influência das expectativas parentais (Santos \& Graminha, 2005), é de fundamental importância que se faça uma discussão acerca disso. No contexto da síndrome de Down, a construção de expectativas em relação ao desenvolvimento e escolarização do filho é influenciada por inúmeras variáveis, tais como: a forma como o diagnóstico é revelado, a condição psíquica da mãe e da família, o apoio 
do entorno familiar, dentre outros. É importante salientar que os pais tomam conhecimento de que seu filho tem síndrome de Down no ato do diagnóstico e esse momento costuma colocar em cheque as expectativas construídas até então. É por essa razão que dentre todos os fatores envolvidos na construção de expectativas, o momento do diagnóstico é um aspecto de extrema relevância.

Nessa perspectiva, autores como Buscaglia (2006), Henn, Piccinini e Garcias (2008), Murphy (1990/1993), Silva e Dessen (2003) e Skotko (2005) salientam a importância do apoio de uma equipe multiprofissional no momento de comunicar o diagnóstico aos pais, uma vez que eles relatam que a notícia raramente é revelada de forma adequada. Diante da notícia, os pais apreendem a síndrome de Down desde um lugar prefixado, preestabelecido, cuja tendência é de aprisionamento (Gumá, 2000). Tal aprisionamento, em geral, está relacionado às impossibilidades associadas à síndrome, as quais estão incorporadas ao imaginário social. O discurso calcado nas impossibilidades é produto de uma visão ultrapassada da síndrome de Down, em um período em que as pessoas com a referida síndrome ficavam privadas de inúmeras interações sociais, fadadas a permanecerem alheias ao social, sendo, portanto, pouco estimuladas. Se outrora os bebês com síndrome de Down nasciam já destinados a permanecer à margem da sociedade, mantendo-se num lugar de exclusão social, atualmente, segundo o estudo de Holden e Stewart (2002), não é mais possível dar uma afirmação precisa sobre o potencial futuro do filho com síndrome de Down. Isso porque o ambiente ocupa lugar de destaque no desenvolvimento. Nesse sentido, um ambiente rico de estímulos e expectativas favorece o desenvolvimento de todas as pessoas, inclusive as com síndrome de Down.

Embora a discussão sobre a forma de revelar o diagnóstico de síndrome de Down seja extremamente relevante, independentemente da forma como ele é comunicado, provoca um abalo, um grande impacto nos pais, uma vez que esse bebê está longe de corresponder às expectativas endereçadas ao bebê imaginário/idealizado (Brasington, 2007; Buscaglia, 2006; Couto, Tachibana, \& Aiello-Vaisberg, 2007; Mannoni, 1964/1995; Sunelaitis, Arruda, \& Marcom, 2007; Welter, Cetolin, Trzcinski, \& Cetolin, 2008). Esse contraste entre o bebê imaginário, depositário dos ideais parentais, e o bebê real, que nasceu com síndrome de Down, desencadeia um processo de luto, pela perda do bebê sonhado. Sendo assim, a presença da síndrome de Down impede que os pais antecipem que esse filho vai corresponder à imagem construída por eles. Não raras vezes, os pais vêem o filho como um impostor, um estranho que está ocupando o lugar daquele filho imaginariamente sonhado, a partir dos ideais parentais (Coriat, 1997; Jerusalinsky, 2002; Jerusalinsky, 1989; Jerusalinsky \& Coriat, 1983; Jiménez, 2000; Mannoni, 1964/1995; Oliveira, 2001; Pérez de Plá, 2000; Schmidt, 1996).
Para os pais, endereçar desejos e expectativas ao bebê constitui-se fonte de angústia, uma vez que há a presença do temor de que a dificuldade possa fazer obstáculo aos ideais acalentados. Esse sentimento de desesperança acompanha os pais e exerce influência na promessa de futuro (Jiménez, 2000; Pérez de Plá, 2000; Schmidt, 1996). Além disso, o forte impacto do diagnóstico, de acordo com Mannoni (1964/1995), faz com que eles cheguem a desejar consciente ou inconscientemente a morte do filho, por acreditarem que este tomou o lugar do filho sonhado.

O estudo de Sunelaitis e cols. (2007) evidencia as repercussões do diagnóstico de síndrome de Down nas expectativas da mãe em relação ao futuro do filho. De acordo com a pesquisa, mães com dificuldade de construir expectativas podem estar manifestando um desconhecimento sobre as possibilidades de desenvolvimento da criança, impossibilitando-as de permanecer numa atitude de aposta e investimento. A pesquisa ainda aponta para a possibilidade de estas mães estarem manifestando uma defesa, diante do diagnóstico de síndrome de Down, estabelecendo, dessa forma, uma relação de medo de cuidar do filho e desesperança em relação ao seu futuro, o que também pode estar atrelado ao desconhecimento sobre as possibilidades de desenvolvimento da criança. É importante mencionar que a pesquisa foi realizada no contexto de uma UTI de um hospital, o que provavelmente, representa um incremento na dor da mãe. Nessa mesma perspectiva, o estudo de Boff e Caregnato (2008) demonstrou que o impacto do diagnóstico e a falta de orientação, por meio de uma abordagem acolhedora e tolerante ao sofrimento alheio, interferem negativamente na construção das expectativas dos pais. A pesquisa de Pereira-Silva e Dessen (2007) ainda revela que a preocupação com o desenvolvimento motor da criança com síndrome de Down apresenta relação com a preocupação e a constituição de expectativas em relação ao futuro dela.

Inúmeros autores evidenciam o impacto do diagnóstico de síndrome de Down nos pais, especialmente, nas mães (Buscaglia, 2006; Couto e cols., 2007; Coriat, 1997; Hastings, Thomas, \& Delwiche, 2002; Hodapp, Ricci, Ly, \& Fidler, 2003; J. Jerusalinsky, 2002; Jerusalinsky, 1989; Jerusalinsky \& Coriat, 1983; Jiménez, 2000; Mannoni, 1964/1995; Oliveira, 2001; Pelchat, Bisson, Bois \& Saucier, 2003; Pérez de Plá, 2000; Ricci \& Hodapp, 2003; Schmidt, 1996; Silva \& Dessen, 2003; Skotko, 2005; Sunelaitis e cols., 2007; Welter e cols., 2008). Sentimentos como o de estranheza, choque, tristeza, decepção e ansiedade são evidenciados por mães que recebem o diagnóstico de síndrome de Down, tendo repercussões na relação mãe-bebê. A pesquisa de Couto e cols. (2007) revela que no que se refere à perda do filho idealizado, a síndrome de Down, nos primeiros meses e, possivelmente, nos primeiros anos, esteve mais presente no olhar das mães entrevistadas do que o filho propriamente dito. Baseado no 
estudo de Santos e Graminha (2005), acreditamos que o fato de o diagnóstico abalar os pais, pode interferir na constituição das expectativas em relação ao desenvolvimento e escolarização do filho. Isso porque partimos do pressuposto de que há influências das expectativas parentais no desenvolvimento e rendimento escolar.

Ter um filho com síndrome de Down e permanecer aprisionado nas impossibilidades pode ter implicações na constituição de expectativas que delineiam o futuro do filho. É nesse sentido que o diagnóstico de síndrome de Down pode traçar um destino para a criança, estando posto a priori inúmeros fracassos nos processos de desenvolvimento e escolarização. Libertar-se dessa sentença é um desafio para os pais, sobretudo, quando a condição psíquica da mãe e da família e o apoio do entorno familiar, já são frágeis, independente da síndrome de Down.

Considerando o papel fundamental da família no desenvolvimento do indivíduo, o presente estudo teve por objetivo investigar as expectativas de mães em relação ao desenvolvimento e escolarização do filho com síndrome de Down.

\section{Método}

\section{Participantes}

O presente estudo contou com a participação de 12 mães com filhos com síndrome de Down, que freqüentam uma associação de pais de pessoas com síndrome de Down, em um município da região metropolitana de Porto Alegre, RS.

A idade das mães variou entre 18 e 53 anos (Tabela 1). Nove das 12 mães que participaram do estudo viviam com o pai do filho com síndrome de Down. Quanto ao nível escolar, nove mães tinha o ensino fundamental incompleto (em média, variando entre $4^{\mathrm{a}}$ a $5^{\mathrm{a}}$ série), uma cursou o ensino fundamental completo, outra concluiu o ensino médio e por fim há uma mãe com nível universitário incompleto. Em média, as mães tinha 2,42 filhos, variando de 1 a 4 . Com a intenção de manter preservada a identidade das participantes, designouse uma letra de "A" a "M" a cada mãe.

Em geral, as crianças com síndrome de Down freqüentam escolas de ensino regular. Nenhum dos bebês com síndrome de Down freqüenta escolas de educação infantil, mas as mães referem que pretendem matriculá-los. Quanto aos três adolescentes com síndrome de Down, um tem acompanhado a escola, outro, com idade superior a 20 anos, há pouco tempo iniciou o processo de alfabetização, e o terceiro adolescente não é alfabetizado e não freqüenta a escola. Ao total, são nove meninos e três meninas com síndrome de Down e suas idades variam entre dois meses a 23 anos $(\mathrm{M}=8,25)$, conforme dados da Tabela 1. Cabe salientar que o estudo considerou bebês, aqueles com idade de zero mês até três anos; crianças, aquelas com idade de quatro anos a 11 anos; e, adolescentes, com idade entre 12 anos a 23 anos.
Tabela 1

Caracterização da amostra por idade

\begin{tabular}{ccc}
\hline Mãe & Idade materna (anos) & Idade do filho com SD \\
\hline A & 38 & 2 meses \\
B & 35 & 3 meses \\
C & 18 & 10 meses \\
D & 43 & 2 anos \\
E & 43 & 6 anos \\
F & 47 & 7 anos \\
G & 44 & 8 anos \\
H & 42 & 8 anos \\
I & 39 & 9 anos \\
J & 46 & 13 anos \\
L & 51 & 21 anos \\
M & 53 & 23 anos \\
\hline
\end{tabular}

\section{Instrumentos}

As participantes preencheram um formulário de informações demográficas e participaram de uma entrevista semiestruturada. As informações demográficas consistiram em um formulário com dados de identificação da mãe, do pai e da criança com síndrome de Down, tais como: nome, idade, escolarização, profissão, com quem vive. Sobre as crianças foi perguntado quanto ao tipo de escola freqüentado pela mesma (regular ou especial). A entrevista semi-estruturada envolveu questões que norteiam o estudo: como as mães percebem e o que esperam em relação ao desenvolvimento e a escolarização do seu filho.

\section{Considerações éticas}

A pesquisa teve início após a assinatura do Termo de Consentimento Livre e Esclarecido. As entrevistas foram gravadas e posteriormente transcritas literalmente. O projeto de pesquisa foi, previamente, aprovado e autorizado pelo Comitê de Ética em Pesquisa da Pró-Reitoria de Pesquisa da Feevale (Processo 7.08.01.05.63).

\section{Procedimentos}

\section{Coleta de dados}

As mães foram recrutadas em uma reunião de pais da associação e todas as mães presentes aceitaram, prontamente, participar do estudo. A associação em questão é uma organização não governamental que trabalha com uma proposta pró-inclusiva, sendo referência para pessoas com síndrome de Down.

\section{Análise dos dados}

Foi realizada uma análise qualitativa de dados, considerando pressupostos teóricos psicanalíticos, sobretudo, 
a questão das expectativas maternas em relação ao filho com síndrome de Down. Em um primeiro momento, todos os dados foram organizados em categorias temáticas, que foram criadas a partir da leitura das entrevistas transcritas, conforme análise qualitativa de conteúdo (Laville \& Dionne, 1997/1999). Posteriormente, realizamos uma articulação com a literatura pesquisada. As categorias temáticas são: impacto do diagnóstico, percepção das mães em relação ao filho com síndrome de Down, investimento no filho com síndrome de Down, expectativas em relação ao desenvolvimento do filho e expectativas em relação à escolaridade do filho. A categoria sobre a percepção materna em relação ao filho com síndrome de Down foi subdividida em subcategorias, de acordo com as diferentes fases do desenvolvimento do filho (bebês, crianças e adolescentes). Tais categorias serão expostas, caracterizadas, exemplificadas e discutidas.

\section{Resultados e Discussão}

\section{Impacto do diagnóstico}

Todas as mães revelaram ter sofrido um impacto diante do diagnóstico de síndrome de Down. O discurso das mães indica que elas foram surpreendidas pelo anúncio da síndrome:

Porque a mãe, também quando ganha ele, pode-se dizer que ela não está preparada para receber um filho portador da síndrome de Down, mas não é de assustar (...). Porque eu sei que houve pais que se queixaram para mim, que nasceu criança no hospital e o médico foi e disse assim ó: você vai ter uma cruz pro resto da vida! Isto não é coisa que se diga, ou: você vai ter um peso pro resto da vida, né? (F. 47 anos, filho de sete anos)

Porque eu, quando tive ele, eu estava com 38 anos, e eu não sabia o que era uma criança com síndrome de Down, né? (...). Hoje eu penso, bah eu fico assim, no inicio, foi bastante chocante assim, fiquei bastante triste, né? Bah, pensei que eu até nem queria mais viver na minha vida, aquilo ali para mim, foi um... né? (E. 43 anos, filho de seis anos)

Podemos perceber que o discurso das mães revela que o diagnóstico de síndrome de Down gera um impacto, que é recordado pelas mães como uma experiência traumatizante (Buscaglia, 2006; Couto e cols., 2007; Coriat, 1997; Hastings e cols., 2002; Hodapp e cols., 2003; J. Jerusalinsky, 2002; Jerusalinsky, 1989; Jerusalinsky \& Coriat, 1983; Jiménez, 2000; Mannoni, 1964/1995; Oliveira, 2001; Pelchat e cols., 2003; Pérez de Plá, 2000; Ricci \& Hodapp, 2003; Schmidt, 1996; Silva \& Dessen, 2003; Skotko, 2005; Sunelaitis e cols., 2007; Welter e cols., 2008). Independentemente da forma como o diagnóstico foi revelado, provocou um choque nas mães. Isso porque as mães não esperam ter um filho com síndrome de Down. Embora o sentimento de despreparo apareça nas falas das mães, há também uma idéia de tentativa de superação, o que ficou evidente na fala da mãe F, quando ela menciona que "não é de assustar".

Problemas de superação do choque vivido no momento do diagnóstico podem representar dificuldades de ver o filho para além do diagnóstico médico, remetendo-nos a pensar na importância de um olhar acolhedor (Boff \& Caregnato, 2008) e de apoio de uma equipe multiprofissional nesse momento tão delicado (Henn e cols., 2008; Murphy, 1990/1993; Silva \& Dessen, 2003; Skotko, 2005).

\section{Percepção das mães em relação ao bebê com síndrome de Down}

As mães relatam maior preocupação em relação ao desenvolvimento físico e motor dos bebês. Apontam receio em lidar com o filho, em função de vê-lo como frágil e com muitas limitações. Ao mesmo tempo, apresentam-se surpresas com a capacidade dos bebês:

Que quando ela era pequeninha eu pensei que ela não ia se desenvolver assim, se mexer do jeito que ela se mexe, se virar na cama do jeito que ela se vira, né?(...). É! Bem quietinha, eu tinha medo de pegar e a gente tem medo de lidar, né? Ela é muito pequeninha! Agora não! Agora ela já está com 51 $1 / 2 \mathrm{~cm}$. Já está com 3 quilos né? Eu não pensei que ela ia se desenvolver tão ligeiro! (A. 38 anos, filho de dois meses)

Coisa que eu pensei que ela não ia fazer, porque eu sei que é mais dificultoso para eles, né? Isto é coisa que pra mim, só o fato dela erguer a mãozinha, fazer isto aqui sabe, fazer tchau, tchau, sabe? Para mim isto aqui é uma vitória, sabe? Coisa que ela tem dificuldade, mas que ela tá fazendo. E se não tivesse na fisioterapia, certamente ela ia ficar sentadinha, num canto ali, cuidar pra não mexer porque ela tem síndrome de Down, e agora não, eu sei que ela pode, sabe? (C. 18 anos filho de dez meses)

As falas das mães evidenciam uma atitude de pouca expectativa em relação ao desenvolvimento de seus bebês, surpreendendo-se quando percebem que os bebês são capazes. Antes mesmo de olhar para o filho, estão presas a uma idéia de impossibilidade, que salienta a síndrome desde um local prefixado, preestabelecido (Gumá, 2000). Parecem estar olhando mais para a síndrome de Down do que para o bebê propriamente dito (Couto e cols., 2007). Embora houvesse a presença de uma visão prévia que apontasse para fracassos, o fato de estarem se deparando com uma realidade que contrasta com tal visão pode auxiliar a mãe a redimensioná-las, possibilitando a constituição de novos desejos, que levem em consideração as capacidades do bebê (Couto e cols., 2007; Mannoni, 1964/1995; Sunelaitis e cols., 2007). As falas também sugerem a importância 
do acompanhamento de um profissional especializado, no sentido de desconstruir o discurso calcado nas impossibilidades e ajudá-las a perceber as potencialidades do filho (Henn e cols., 2008).

\section{Percepção das mães em relação à criança com síndrome de Down}

Nesta fase do desenvolvimento, as mães relatam preocupação em relação à aprendizagem, à escola e à inclusão do filho com síndrome de Down. As falas colocam em evidência a importância que a escola regular tem para as mães de crianças com síndrome de Down:

Daqui para frente eu acho que vai ser para melhor, né? Porque cada vez que ele está passando, ele está crescendo, depois que ele foi na escola (...) ele vê o que as outras criancinhas fazem e ele quer fazer. (...) Acho muito importante eles participarem de uma escola normal. (...) As crianças normais, elas têm aquele desenvolvimento a mais para passar para as crianças, então eles já aprendem mais, a conhecer, a brincar, até de fazer um trabalhinho, eles ficam observando. (E. 43 anos, filho de seis anos)

Eu penso que hoje ele está no pré, ano que vem ele vai para primeira série, o pré não roda, mas a primeira série pode rodar, né? Então, não vai me assustar, se rodou, rodou. Estou preparada para isto também, psicologicamente, mas eu quero ajudar bastante ele. Eu estou preparada. (...) Se ele acontecer de um ano ele rodar em qualquer série, não vai me incomodar, rodou, rodou. (F. 47 anos, filho de sete anos)

O discurso materno evidencia que as mães parecem estar olhando para o filho para além das impossibilidades, demonstrando estarem mais livres de estigmas e podendo, então, apostar nas capacidades do filho. Destacamos também a preocupação das mães em relação à aprendizagem e à importância atribuída à escola nessa fase do desenvolvimento.

No entanto, um fator que pode gerar angústia nas mães é o desempenho escolar do filho, uma vez que uma das características da síndrome de Down é a deficiência mental (Fidler, 2005; Motta, 2005). Tal limitação, entretanto, é variável e não é produto somente do orgânico, mas também do ambiente (Gumá, 2000; Jiménez, 2000; Pérez de Plá, 2000). Crianças com deficiência mental não estão, necessariamente, impedidas de aprender. Muitas vezes, elas necessitam de um olhar especializado e, principalmente, de alguém que acredite em suas capacidades. Nesse sentido, sustentar uma posição de aposta às potencialidades do filho pode auxiliá-lo a enfrentar os obstáculos que podem surgir, sobretudo, em função da deficiência mental (Fidler, 2005; Santos \& Graminha, 2005).

\section{Percepção das mães em relação ao adolescente com síndrome de Down}

As mães relatam preocupação em relação à transição da adolescência para a vida adulta, através de questões que envolvem trabalho, namoro, constituição familiar:

Eu espero que ela consiga para ela mesma, não tanto para mim, que ela consiga estudar para ela conseguir trabalhar, né? Porque o incentivo dela é trabalhar, né? Trabalhar, namorar, né? Ter familia, ter filhos, tudo isto ela programa, ela fala, né? Eu acho assim, que a gente sempre espera que ela consiga, né? Porque a gente sempre tentou ajudar, né? Em tudo que a gente pode, né? (J. 46 anos, filho de 13 anos)

Então agora ele se vendo trabalhando, ele me fazia perguntas assim, quando é que eu vou namorar? (...) quando é que eu vou tirar minha carteira de motorista? (...) então a questão da namorada, assim realmente, agora ele está namorando, no início assim, para mim foi uma coisa meio nova. (...). E para mim foi um desafio novo! (...) Ele tem sonhos de casar, né? A gente quer ver se consegue, até no bom sentido assim ó, construir, tanto a família dela (da namorada, que também tem síndrome de Down) quanto a minha a gente vai ver isto para um futuro, porque eles já têm planos para isto já está bem... hã de casarem, né? Terem a vida deles... só que assim, eu não sei se a gente vai dar tanta autonomia que nós vamos deixar ele ir fora, quem sabe assim ó, construir no pátio da nossa casa (...) alguma coisa assim, que eles vão ter a autonomia deles, mas que a gente vai projetando e dando uma segurança e, ao mesmo tempo tu vai dando este apoio para eles terem uma vida independente. (M. 53 anos, filho de 23 anos)

As falas das mães denotam uma contradição. Ao mesmo tempo em que falam de autonomia, denunciam temores em relação a isso, falando de uma espécie de autonomia vigiada. O estudo de Blacher, Kraemer e Howell (2010) também demonstra algumas contradições, evidenciando, por exemplo, que embora as mães de jovens com síndrome de Down apresentem expectativas otimistas em relação a trabalho, têm dificuldades de supor que o(a) filho(a) more longe delas. As mães de nosso estudo percebem que o filho cresceu e que começa a desejar coisas que um jovem de sua faixa etária almeja, mas se questiona sobre as reais condições de o filho dar conta de seus ideais. Isso se dá muito provavelmente porque algumas questões que giram em torno da adolescência, sobretudo, o que diz respeito à sexualidade, são uma espécie de tabu para os pais, como se eles não pudessem ascender à adolescência (Schmidt, 1996). 


\section{Investimento no filho com síndrome de Down}

A questão do investimento no filho com síndrome de Down apareceu com freqüência nas falas das mães. Elas acentuaram a necessidade de investir em seu filho, em função de suas limitações. Alguns relatos apresentaram uma entrega quase que absoluta das mães aos cuidados dos filhos: "daqui pra frente eu tenho que cuidar dele. Investir tudo nele (...) viver só para ele, porque ele precisa." (B. 35 anos, filho de três meses de idade)

As mães também mencionaram investir no aprendizado e nas potencialidades do filho com síndrome de Down, preocupando-se com o desempenho e convívio escolar. Para tanto, buscam cursos e outras atividades, pois acreditam que certas habilidades do filho com síndrome de Down possam assim ser conquistadas para além da escola e da casa.

Agora eu quero ver se boto ele numa aula de futebol, tem aula de música, isto ai é muito importante, isto ai eu também penso bastante, para ele (...). Até eu estava pensando, agora quando eu sair, passar e comprar um microfone, porque ele adora, ele liga no som... isto para a linguagem dele é bom, né? (F. 47 anos, filho de sete anos)

Os dados revelaram que o discurso vigente é de investir no filho, através de inúmeros atendimentos e atividades extraclasse. Algumas mães chegam a abandonar o trabalho e demais atividades que faziam antes de o filho nascer, para poder ter mais tempo para se dedicar a ele. Entendemos que cada caso deva ser olhado singularmente, uma vez que tal investimento e dedicação parecem revelar diferentes formas de lidar com o sofrimento causado pelo diagnóstico de síndrome de Down. Nesse sentido, assim como uma mãe pode estar de fato apostando no desenvolvimento do filho, envolvendo-se com os atendimentos e atividades, outra mãe pode, aparentemente, providenciar inúmeras formas de mantê-lo ocupado, para não se confrontar com ele, na medida em que o filho representa o seu sofrimento, outra mãe ainda pode oferecer inúmeras atividades e tratamentos ao filho, numa tentativa de que os mesmos apaguem a diferença, sendo ela sentida como algo insuportável.

Inevitavelmente a síndrome de Down marca uma diferença. Diferença que não está exposta somente nas características faciais, mas também nas suas condições cognitivas. A deficiência mental, como já colocado, é variável e produto também do ambiente (Gumá, 2000; Jiménez, 2000; Pérez de Plá, 2000). Nesse sentido, é fundamental que a criança possa ser olhada como ela é, com suas limitações, mas sem desconsiderar suas possibilidades. Para isso, é necessário um desprendimento em relação àquilo que foi prefixado e preestabelecido pelo discurso social. É a partir do reconhecimento das possibilidades da criança que se pode construir novas expectativas e desejos ao filho, sendo isso determinante na sua constituição psíquica (Coriat, 1997; J. Jerusalinsky, 2002; Jerusalinsky, 1989; Jerusalinsky \& Coriat, 1983; Mannoni, 1964/1995).
Na medida em que o diagnóstico de síndrome de Down ocupa um lugar de verdade absoluta, aprisiona os pais na informação daquilo que está deficiente, nas limitações e impossibilidades do filho (Silva \& Dessen, 2003; Skotko, 2005). Em função disso, os pais ficam impedidos de construir discursos antecipatórios e alimentar aspirações e promessas de realizações futuras (Oliveira-Menegotto, 2006). Por outro lado, os pais podem estar investindo em aulas particulares, atividades extraclasse, mas com a idéia de subjacente de não suportar a diferença. Aquilo que parece ser uma aposta nas potencialidades do filho pode estar representando uma tentativa desenfreada de apagar as diferenças, por não estar conseguindo acolher o filho, como ele é.

\section{Expectativas em relação ao desenvolvimento do filho}

Percebemos que as mães demonstraram dificuldade em expor suas expectativas e pensar sobre o futuro de seus filhos. Algumas mães permanecem aprisionadas àquilo que está prefixado e preestabelecido socialmente em relação à síndrome de Down, tendo dificuldades de criar e apostar em algumas expectativas em relação ao futuro do filho (Gumá, 2000). Permanecer presa ao presente, sem conseguir vislumbrar possibilidades futuras ao filho, parece ser uma forma de se proteger do sofrimento e frustração decorrentes do diagnóstico de síndrome de Down. Nesse sentido, a dificuldade de construir expectativas futuras para o filho parece ser uma expressão da dificuldade de implicação no futuro dos mesmos (Jiménez, 2000; Pérez de Plá, 2000; Schmidt, 1996). Tal dificuldade se manifesta quando as mães afirmam que, ao invés de vislumbrar possibilidades futuras na vida do filho, permanecem numa posição de aguardo daquilo que o filho pode mostrar, não conseguindo apresentar uma atitude de aposta e investimento em relação ao futuro do filho (Sunelaitis e cols., 2007): "cada fase é uma fase, tu tem que ir esperando conforme ele vai mostrando, né?... Sei lá, nunca pensei assim, no que poderia ser, né? Tudo eu vou esperando as fases vão acontecendo." (H. 42 anos, filho de oito anos)

Percebemos também que algumas mães conseguem construir expectativas em relação ao futuro do filho, embora a expressão "criança" seja recorrente em seu discurso, apontando para uma contradição. Ao mesmo tempo em que as mães constroem expectativas, não conseguem apostar na idéia de que o filho vai crescer e deixar de ser criança. Ainda que as mães consigam vislumbrar e antecipar possibilidades para o filho no futuro, não podemos deixar de salientar que elas apresentam dificuldades em vê-los para além da infância (Schmidt, 1996).

Que um dia que ele for pegar um trabalho (...) saiba chegar lá, saiba pegar um ônibus, né? Saiba o lugar em que ele vai, né? E isto a gente espera dele, né? (...) Eu espero dele que eu possa dizer para ele ir ao mercado sozinho (...). Que se eu disser assim: tu vai lá no centro, pega o ônibus e vai em tal lugar, né? Isto é o que a gente espera dele, sempre para 
melhor, né? (...) Em casa também que eles sejam crianças mais responsáveis que eles saibam o que eles devem e o que ele não devem fazer, o que é perigoso. (...) Que se ele tem vontade de tomar banho, que ele tome banho sozinho, que se ele tem vontade de comer alguma coisa que ele vá ali arrumar e vai comer sozinho. (...) Que eles conquistem o espaço deles e que eles assim... responsáveis por eles mesmo, né? (...) Eles têm que pelo menos saber se defender, né? (E. 43 anos, filho de seis anos)

A construção das expectativas em relação ao desenvolvimento do filho é, na maioria das vezes, abalada em função do desconhecimento sobre as possibilidades de desenvolvimento da criança (Sunelaitis e cols., 2007). Isso porque as mães ainda estão muito tomadas por aquilo que está prefixado e preestabelecido socialmente para pessoas com síndrome de Down, sem conseguir perceber o filho para além disso. Sendo assim, criar expectativas em relação ao futuro do filho constitui-se fonte de angústia, em função de que o temor em relação às impossibilidades apontadas no diagnóstico possam se colocar como impasse aos ideais acalentados (Jiménez, 2000; Pérez de Plá, 2000; Schmidt, 1996).

\section{Expectativas em relação à escolarização do filho}

$\mathrm{O}$ discurso das mães evidenciou que elas apresentam dificuldades em construir expectativas em relação à escolarização do filho. Algumas mães relataram que matriculam seus filhos no ensino regular, mas sem considerar a prosperidade do ensino e aprendizagem: "não tenho muita esperança que ele vai aprender, assim... porque a gente vê, né? Porque geralmente a criança com oito anos, já sabe escrever seu nome, já esta lá na primeira série, passando para a segunda." (G. 44 anos, filho de oito anos)

Percebemos que essa fala denuncia o quanto o estigma da deficiência mental e da impossibilidade está presente no imaginário materno. Embora as pessoas com síndrome de Down tenham limitações de ordem cognitiva, é fundamental fazer uma aposta, acreditando que o filho também apresenta potencial para aprendizagem, uma vez que a visão da limitação marcada no olhar materno pode enquadrar o filho numa idéia de fracasso a priori. Uma mãe que se prende somente às limitações pode dificultar, ou até mesmo impedir a construção de expectativas. É como se diante de um maior desafio, como, por exemplo, a escolarização, não valesse à pena apostar no filho, mantendo-se numa postura de desesperança (Jiménez, 2000; Pérez de Plá, 2000; Schmidt, 1996), sobretudo, em relação ao potencial de aprendizagem do filho.

Dentre as mães que conseguiram estabelecer expectativas em relação à escolarização do filho, algumas apontaram a alfabetização e operação de cálculos matemáticos simples, como suficientes para que os filhos possam alcançar autonomia e independência. Sendo assim, apesar de elas mencionarem esperar que os filhos aprendam questões relacionadas à vida cotidiana, tais expectativas ainda são muito limitadas, denotando, novamente, uma dificuldade das mães em apostar no futuro dos filhos.

Eu espero que ele aprenda a se virar sozinho, a saber fazer uma conta, né? Poder pegar uma coisa na rua, fazer, receber o troco, saber o que esta certo, né? Agora saber nome de rio, nome de rio afluente, de rio Amazonas ou quanto vale " $x$ ", se o " $x$ " vale "y”, sei lá... esta questão não é importante para ele, né? É a questão do dia a dia é que ele tem que aprender. (I. 39 anos, filho de nove anos)

A fala acima aponta que embora as expectativas construídas pelas mães sejam modestas, percebemos que há uma aposta na escolarização como fator fundamental na conquista da autonomia. Dentre outros fatores, o que pode prejudicar a escolarização do aluno com síndrome de Down, no entanto, é a dificuldade dos pais em apostar na capacidade de aprendizagem do filho, uma vez que as expectativas são fundamentais para o desenvolvimento (Santos \& Graminha, 2005). Sabemos, no entanto, que além da atitude de aposta e investimento dos pais (Sunelaitis e cols., 2007), é necessário que os professores também possam constituir expectativas em relação à escolarização do aluno com síndrome de Down, olhando-o para além da síndrome. Além disso, a escola deve permanecer aberta ao diálogo com a família e com os profissionais da saúde. Nessa perspectiva, o estudo de Yssel, Engelbrecht, Oswald, Eloff e Swart (2007) revela que a parceria entre a escola e a família é essencial para o sucesso de uma proposta inclusiva.

\section{Considerações finais}

Os resultados desta pesquisa revelaram que o diagnóstico de síndrome de Down, independentemente de como é revelado, causa um impacto nas mães, que é sentido, apesar da passagem do tempo, como um evento traumático e fonte de dor e sofrimento. Afinal, o bebê com síndrome de Down está longe de corresponder aos ideais construídos pela mãe.

O maior desafio encontrado nesses casos, é que o diagnóstico pode acabar selando um destino para a pessoa com síndrome de Down. Isso porque, os pais, não raramente, permanecem aprisionados a uma visão de fracasso, podendo ter efeito no estabelecimento de expectativas em relação ao futuro do filho.

As percepções maternas em relação ao filho com síndrome de Down variam em cada fase do desenvolvimento e o luto também parece ser revivido em cada fase em que o filho está. Pensamos, a partir disso, que não há uma aceitação total da síndrome de Down, uma vez que as mães constantemente se deparam com obstáculos e decepções, sendo o luto retomado em cada fase, diante de novos desafios. Quando os filhos são bebês, as mães se deparam, principalmente, com a defasagem motora, através de atrasos do desenvolvimento neuropsicomotor, tais como sentar, engatinhar e caminhar. 
Na idade escolar, as mães se deparam com as dificuldades impostas pela deficiência mental, tais como as defasagens na aprendizagem. E, por fim, na adolescência, as mães se deparam, sobretudo, com questões referentes a trabalho, namoro e constituição familiar. Ainda foi possível observar que apesar de o filho estar na adolescência, as mães apresentam dificuldades de percebê-lo como adolescente, referindo-se a ele como criança. Este aspecto parece ser fundamental no discurso das mães, na medida em que revela a dificuldade de supor que, apesar das limitações impostas pelo orgânico, o filho pode se desenvolver, embora num ritmo próprio. Por outro lado, também foi possível verificar tentativas de superação dos obstáculos e desafios colocados nas fases anteriores.

O estudo contribui para a reflexão da importância de uma equipe de especialistas que possa realizar o apoio e acompanhamento das mães, auxiliando-as no exercício da maternidade, ao longo do desenvolvimento do bebê, bem como na constituição de expectativas relativas ao desenvolvimento e escolarização. Da mesma forma, entendemos ser fundamental trabalhar com os professores, apontando que problemas de aprendizagem podem estar ligados à relação mãe-filho e não somente à deficiência mental. Assim, podemos evitar ou minimizar a reprodução, por parte dos professores, da dificuldade de criar expectativas em torno do desenvolvimento e aprendizagem do aluno com síndrome de Down.

Cabe também mencionar que as dificuldades observadas nas falas das mães pesquisadas podem igualmente ocorrer em mães de filhos ditos normais. Problemas na constituição de expectativas em relação ao desenvolvimento e à escolarização do filho, nesse sentido, não dependem necessariamente da deficiência do filho e sim da forma como a mãe deseja e vê o filho.

Embora o estudo apresente contribuições importantes, temos ciência de que a metodologia adotada apresenta inúmeras limitações. Talvez a maior delas seja o fato de nossas participantes fazerem parte de um movimento associativo, que luta pela inclusão das pessoas com síndrome de Down e que oferece atendimentos às pessoas com síndrome de Down e grupo de pais, representando, dessa forma, um viés. Sugerimos, portanto, a realização de outros estudos que possam investigar estas questões, utilizando uma amostra mais diversificada e propondo mais momentos de coleta de dados, articulando outros instrumentos, tais como, observações, no sentido de ter outras fontes de informação.

\section{Referências}

Blacher, J., Kraemer, B. R., \& Howell, E. J. (2010). Family expectations and transition experiences for young adults with severe disabilities: Does syndrome matter? Advances in Mental Health and Learning Disabilities, 4(1), 3-16.

Boff, J., \& Caregnato, R. C. A. (2008). História oral de mulheres com filhos portadores de síndrome de Down. Texto \& Contexto Enfermagem, 17, 578-586.
Brasington, C. K. (2007). What I wish I knew then... Reflections from personal experiences in counseling about Down Syndrome. Journal of Genetic Counseling, 16, 731-734.

Buscaglia, L. (2006). Os deficientes e seus pais. Rio de Janeiro: Record.

Coriat, E. (1997). Psicanálise e clínica de bebês (J. Jerusalinsky, Trad.). Porto Alegre: Artes e Ofícios. (Original publicado em 1997)

Couto, T. H. A. M., Tachibana, M., \& Aiello-Vaisberg, T. M. J. (2007). A mãe, o filho e a síndrome de Down. Paidéia (Ribeirão Preto), 17, 265-272.

Fidler, D. J. (2005). The emerging Down Syndrome behavioral phenotype in early childhood complications for practice. Infants \& Young Children, 18(2), 86-103.

Gumá, M. L. O. (2000). El impacto del cuerpo. In E. Pérez de Plá \& S. C. Hernández (Orgs.), Sujeto, inclusión y diferencia: Investigación psicoanalítica y psicosocial sobre el Síndrome de down y outros problemas del desarrollo (pp. 97-127). Ciudad del México, México: Universidad Autônoma Metropolitana, Unidad Xochimilco.

Hastings, R. P., Thomas, H., \& Delwiche, N. (2002). Grandparent support for families of children with Down's síndrome. Journal of Applied Research in Intellectual Disabilities, 15, 97-104.

Henn, C. G., Piccinini, C. A., \& Garcias, G. L. (2008). A família no contexto da síndrome de Down: Revisando a literatura. Psicologia em Estudo, 13, 485-493.

Hodapp, R. M., Ricci, L. A., Ly, T. M., \& Fidler, D. J. (2003). The effects of the child with Down síndrome on maternal stress. British Journal of Developmental Psychology Society, 21, 137-151.

Holden, B., \& Stewart, P. (2002). The inclusion of students with Down syndrome in New Zealand schools. Down Syndrome News and Update, 2, 24-28.

Jerusalinsky, A. N., \& Coriat, E. (1983). Função materna e estimulação precoce: Experiência controlada com 100 sujeitos de 3 a 16 meses de idade cronológica. Escritos da Criança, 1, 76-85.

Jerusalinsky, A. N. (1989). A direção da cura do que não se cura. In A. N. Jerusalinsky (Org.), Psicanálise e desenvolvimento infantil (pp. 56-71). Porto Alegre: Artes Médicas.

Jerusalinsky, J. (2002). Enquanto o futuro não vem: A psicanálise na clínica interdisciplinar com bebês. Salvador: Ágalma.

Jiménez, A. F. (2000). El niño con síndrome de Down y sus padres. In E. Pérez de Plá \& S. C. Hernández (Orgs.), Sujeto, inclusión y diferencia: Investigación psicoanalitica y psicosocial sobre el síndrome de down y otros problemas del desarrollo (pp. 141-156). Ciudad del México, México: Universidad Autônoma Metropolitana, Unidad Xochimilco. 
Laville, C., \& Dionne, J. (1999). A construção do saber: Manual de metodologia da pesquisa em ciências humanas (H. Monteiro \& F. Settineri, Trad.). Porto Alegre: Artmed. (Original publicado em 1997)

Luiz, F. M. R., Bortoli, P. S., Floria-Santos, M., \& Nascimento, L. C. (2008). A inclusão da criança com Síndrome de Down na rede regular de ensino: Desafios e possibilidades. Revista Brasileira de Educação Especial, 14, 497-508.

Mannoni, M. (1995). A criança retardada e a mãe (M. R. G. Duarte, Trad.). São Paulo: Martins Fontes. (Original publicado em 1964)

Motta, P. A. (2005). Genética humana aplicada à psicologia e toda a área biomédica. Rio de Janeiro: Guanabara Koogan.

Murphy. A (1993). Nasce uma criança com síndrome de Down. In S. M. Pueschel (Org.), Sindrome de Down: Guia para pais e educadores (pp. 23-31). Campinas, SP: Papirus. (Original publicado em 1990)

Oliveira, L. M. (2001). O desejo parental diante do impacto do diagnóstico de Síndrome de Down. Dissertação de mestrado não-publicada, Universidade Federal do Rio Grande do Sul, Porto Alegre.

Oliveira-Menegotto, L. M. (2006). Da filiação à inclusão: Uma articulação entre psicanálise e educação. In E. P. G. de Moura (Org.), Educação, cultura e trabalho (pp. 8996). Novo Hamburgo, RS: Feevale.

Omote, S., Oliveira, A. A. S., Baleotti, L. R., \& Martins, S. E. S. O. (2005). Mudança de atitudes sociais em relação à inclusão. Paidéia (Ribeirão Preto), 15, 387-398.

Pelchat, D., Bisson, J., Bois, C., \& Saucier, J. (2003). The effects of early relational antecedents and other factors on the parental sensitivity of mothers and fathers. Infant and Child Development, 12, 27-51.

Pereira-Silva, N. L., \& Dessen, M. A. (2007). Crianças com e sem síndrome de Down: Valores e crenças de pais e professores. Revista Brasileira de Educação Especial, 13, 429-446.

Perez de Plá, E. (2000). El sujeto, el cuerpo y el outro: La constitución subjetiva de los niños con problemas del desarrollo, con especial énfasis en el Síndrome de Down. In E. Pérez de Plá \& S. C. Hernández (Orgs.), Sujeto, inclusión y diferencia: Investigación psicoanalitica y psicosocial sobre el Síndrome de Down y otros problemas del desarrollo (pp. 23-95). Ciudad del México: Universidad Autónoma Metropolitana, Unidad Xochimilco.

Ricci, L. A., \& Hodapp, R. M. (2003). Fathers of children with Down syndrome versus other types of intellectual disability: Perceptions, stress and involvement. Journal of Intellectual Disability Research, 47, 273-284.

Santos, S., \& Graminha, V. (2005). Estudo comparativo das características do ambiente familiar de crianças com alto e baixo rendimento acadêmico. Paidéia (Ribeirão Preto), 15, 217-226.
Schmidt, A. P. (1996). Ainda sobre a questão da sexualidade do deficiente mental. Escritos da Criança, 4, 70-75.

Silva, N. L. P., \& Dessen, M. A. (2003). Crianças com síndrome de Down e suas interações familiares. Psicologia: Reflexão e Crítica, 16, 503-514.

Skotko, B. (2005). Mothers of children with Down syndrome reflect on their postnatal support. Pediatrics, 115, 64-77.

Sunelaitis, R. C., Arruda, D. C., \& Marcom, S. S. (2007). A repercussão de um diagnóstico de síndrome de Down no cotidiano familiar: Perspectiva da mãe. Acta Paulista de Enfermagem, 20, 264-271.

Welter, I., Cetolin, S. F., Trzcinski, C., \& Cetolin, S. K. (2008). Gênero, maternidade e deficiência: Representação da diversidade. Revista Textos \& Contextos, 7, 98-119.

Yssel, N., Engelbrecht, P., Oswald, M. M., Eloff, I., \& Swart, E. (2007). Views of Inclusion: A comparative study of parents' perceptions in South Africa and the United States. Remedial and Special Education, 28, 356-365.

Laura Kolberg Lipp é graduada em Psicologia pela Universidade Federação de Estabelecimentos de Ensino Superior em Novo Hamburgo (Feevale).

Fernanda de Oliveira Martini é graduada em Psicologia pela Universidade Federação de Estabelecimentos de Ensino Superior em Novo Hamburgo (Feevale).

Lisiane Machado de Oliveira-Menegotto é Professora Doutora do curso Psicologia da Universidade Federação de Estabelecimentos de Ensino Superior em Novo Hamburgo (Feevale).
Recebido: 07/05/2008
$1^{a}$ revisão: 09/02/2009
$2^{a}$ revisão: 08/12/2009
$3^{a}$ revisão: 03/04/2010
Aceite final: 09/05/2010 